\title{
Results Regarding the Phenotypic Correlations between Quantitative Characters of Interest in Improving Gladiolus Hybrids
}

\author{
Denisa Andrea JUCAN $\left(\mathrm{HORT}^{1}\right)^{1}$, Maria CANTOR ${ }^{1}$, Adrian ZAHARIA ${ }^{1 *}$, Erzsebet BUTA ${ }^{1}$ \\ ${ }^{1}$ Department of Ornamental Plants. University of Agricultural Sciences and Veterinary Medicine, 3-5 \\ Mănăştur Street, Cluj-Napoca, Romania; \\ *)Corresponding author, e-mail: adrian.zaharia@gmail.com
}

BulletinUASVM Horticulture 72(2) / 2015

Print ISSN 1843-5254, Electronic ISSN 1843-5394

DOI:10.15835/buasvmcn-hort:11387

\begin{abstract}
To determine the intensity of the relationship between two variables forming a normal dimensional distribution the correlation coefficient ( $\mathrm{r}$ ) was calculated. Using empirical data recorded from the field, direct correlations were performed between four characters ( $(a \times b),(b \times d),(a \times c)(c \times d))$ and were obtained both positive and negative values of the coefficient of correlation having different degrees of signification. The greatest value of the $r=0.91$ was founded in variety Early Riser, being distinctly significant. The total height of the plant directly influences the length of inflorescence.
\end{abstract}

Keywords: correlation coefficient, influence, probability, significance.

\section{Introduction}

In the modern era, floriculture is gaining importance as a good source of income apart from giving pleasure and happiness. In this regard, Gladiolus or sword lily (Gladiolus spp.) has gained much importance as a cut flower or for garden display (Bhajantri, 2006). Gladiolus includes widely cultivated and economically important flowering species. The luxuriance unique colourful spikes of some height demanding Gladiolus cultivars have attained immense importance in the community of flower lovers (Nasir et al., 2012).

\section{Aims and objectives}

The aim of the experiment was to determine the extent of the development of which character influences the development of another. Knowing this, it can be decides the method of selection during the breeding process.

\section{Materials and Methods}

In order to determine the level of the relationship between two variables which form a normal two-dimensional distribution, the correlation coefficient (r) was calculated. The calculations were made using empirical data from 10 plants within each variety. The results were compared with the probability of 5\% and $1 \%$ chance to appear in an ideal statistical population where, between variables there is no real connection (Ardelean et al., 2010).

\section{Results and Discussion}

Direct correlations were performed between four characters of interest: total height of the plant $\mathrm{x}$ floral stem length, floral stem length $\mathrm{x}$ diameter of the flower, total height of the plant $x$ the number of flowers in inflorescence, the number of flowers in inflorescence $\mathrm{x}$ diameter of the flower. Both positive and negative values of the coefficient of correlation having different degrees of signification were obtained. In the case of the first correlation, the values of $r$ varies between 0.27 and 0.91 .

The correlation coefficient for plant height with stem length (Tab. 1), has no significant values (between 0.27 and 0.60 ) in the varieties: Nova Lux, Madonna, Cipriana, Fidelio, Plumtart, Praha, but was significant in the case of White Prosperity (0.71) and Oscar (0.73) or even highly distinct 
Tab. 1. The correlation coefficient ( $\mathrm{r}$ ) on four phenotypic correlated characters

\begin{tabular}{|c|c|c|c|c|c|}
\hline \multirow{2}{*}{ Nr. crt } & \multirow{2}{*}{ Cultivar } & \multicolumn{4}{|c|}{ Values of $r$ on phenotypic analysed characters } \\
\hline & & $\mathrm{a}^{1} \mathrm{xb}$ & $\mathrm{bxd}$ & $\mathrm{axc}$ & $\mathrm{cxd}$ \\
\hline 1. & White Prosperity & $0,71^{*}$ & 0,45 & $-0,02$ & $-0,16$ \\
\hline 2. & Nova Lux & 0,37 & $-0,56$ & $0,64^{*}$ & $-0,61$ \\
\hline 3. & Madonna & 0,54 & 0,10 & 0,50 & $-0,20$ \\
\hline 4. & Cipriana & 0,43 & $-0,25$ & $0,73^{*}$ & $-0,71^{\circ}$ \\
\hline 5. & Fidelio & 0,59 & $0,65^{*}$ & 0,35 & 0,48 \\
\hline 6. & Plumtart & 0,27 & 0,35 & 0,38 & $-0,17$ \\
\hline 7. & Praha & 0,60 & $-0,42$ & 0,46 & $-0,06$ \\
\hline 8. & Expresso & $0,98^{* *}$ & 0,57 & 0,59 & $0,75^{* *}$ \\
\hline 9. & Oscar & $0,73^{*}$ & $0,81^{* *}$ & 0,60 & $0,66^{*}$ \\
\hline 10. & Princess M. Rose & $0,81^{* *}$ & $0,88^{* *}$ & 0,54 & 0,59 \\
\hline 11. & Early Riser & $0,91^{* *}$ & $0,65^{*}$ & 0,49 & 0,24 \\
\hline
\end{tabular}

significant in three varieties: Princess Margaret Rose, Early Riser and Expresso (0.81 to 0.98). Given that 5 of the 11 analyzed varieties have statistically ensured correlations and the absence of negative correlation coefficient, it can be concluded that the total height of the plant directly influences the length of inflorescence.

The varieties Nova Lux (-0.56), Cipriana $(-0.25)$, Praha $(-0.42)$ reached negative values that are smaller than the probability of $5 \%=0.63$. Other varieties, having positive values between 0.10 and 0.57 , are: White Prosperity, Madonna, and Plumtart, but they are not statistically ensured. Significant correlation was recorded for the varieties Fidelio and Early Riser, the correlation coefficient being 0.65 . Distinctly significant correlations were observed only in the case of varieties, Oscar and Princess Margaret Rose, where $r$ has values between 0.81 and 0.88 . On Early Riser and Fidelio varieties the analyze shows a significant correlation, which means that in these two cases, with the increase of the plant height, increases the number of flowers in inflorescence.

From the results it can be seen that in 8 of the 11 cases studied, the correlation is not significant, which means that, between those two characters there are no close links. The variety, Oscar $(r=0.66)$ has significantly positive correlation, therefore, there is a real link between the number of flowers in inflorescence and the flower diameter. About variety Cipriana, which registered a significant negative correlation $(r=-0.71)$, it can be said that the greater the number of flowers in inflorescence is, the flower diameter decreases. For variety Expresso $(r=0.75)$, the correlation coefficient is distinctly significant positive, the value is indicating a close link between the number of flowers in inflorescence, as it grows, increases the diameter of the flower.

Other studys on the association of various morphological traits through correlation in Gladiolus showed that, plant height, spike length, floret length, and rachis length had positive and significant correlations (Balaram and Janakiram, 2009).

\section{Conclusion}

Total height of the plant directly influences the length of inflorescence, thus the increasing of the value of the first character automatically determines the growth of the second one.

\section{REFERENCES}

1. Ardelean M, Sestraș R, Cordea M (2007). Horticulture experimental tehnique, Ed. AcademicPres, Cluj-Napoca.

2. Bhajantri, A (2006). Evaluation of Gladiolus hybrids (Gladiolus hybrids hort.) for yield and quality cut flower production, PhD Diss.

3. Nasir IA, Arshad J, Ziaur R , Tayyab H (2012). Molecular analyses of Gladiolus lines with improved resistance against Fusarium wilt. Pak. J. Bot., 44(1): 73-79.

4. Balaram MV, Janakiram T (2009). Correlation and path coefficient analysis in Gladiolus. Journal of Ornamental Horticulture 12(1):22-29. 